\title{
The Scope of Values and Limits of the Personal Psychological Space of Students-Emigrants
}

Belousova A.K.*

Mozgovaya N.N.

Barsukova O.V.

Vyshkvyrkina M.A.

Kryschenko E.P.

Mochalova Yu.A.

Pavlova T.V.

Tushnova Yu.A.

Southern Federal University, Academy of Psychology and Pedagogy, Rostov-on-Don, Russia *Email: belousovaak@gmail.com

Doi:10.5901/mjss.2015.v6n4s3p379

\section{Abstract}

This article analyzes theoretical and empirical works of personality psychology, personal psychological space, value and sense bearing sphere of students-emigrants. Within the empirical study of formation of value and sense bearing sphere of studentsemigrants of the second-fourth years of study in the pedagogical high school of the Southern Federal University, results in revealing not only the dynamics of these processes, but also the development of the personal psychological space contents and its boundaries were obtained. The analysis of this issue showed that the value and sense bearing sphere of a person has a forming effect on the components of the personal psychological space. The personal space takes place at all stages of the ontogenetic development. It has the most vivid expression at time of being a student. Also, connections between the values of students-emigrants and the formation of their personal psychological space were found.

Keywords: personal psychological space, subject, values, spheres of life activity, students-emigrants

\section{Introduction}

Russian society imposes new requirements to the modern higher education which include not only the formation of knowledge and skills of studying young people, but also their personal formation, the development of qualities enabling the new generation to actualize and realize them to the maximum extent in the existing socio-economic and professional space of the high school. As practice shows, for the modern person it is not enough just to become a subject or a person, today the person has to go beyond these limits and create something new, namely, the personal psychological space. Also, the ability to observe the boundaries of such space in the modern intercultural, intersocial and international space of the high school is required. Personal psychological space is subjectively meaningful fragment of life that determines the activity and strategy of human life. Psychological space includes a set of physical, social and purely psychological phenomena and they facilitate person to identify oneself (territory, personal objects, social attachment, attitudes).

\section{Methodological Framework}

Theoretical and methodological base of the research is "social space" by G. Simmel and P. Bourdieu, "Lebensraum or psychological field" by K. Levin and "psychological personality space" by S.K. Nartova-Bochaver.

The personal psychological space is characterized as a complex, integrated psychological formation being a result of individual subjectivity development (Mozgovaya, 2002). On the one hand, it ensures its integrity, keeping of identity, 
the ability to self-presentation, self-protection from the manipulative and any negative impact from other persons. On the other hand, the personal space contributes to the formation of a whole complex of moral and ethical, personally significant and individually meaningful distinctive features and properties of a human.

The existence of the individual psychological space is a significant and indisputable fact. However, this evidence is illusory enough, because any attempts to operationalize it face irresistible obstacles, the main of which is its variability. The psychological space phenomenon is definitely lost in the range of the human complex psychological reality. Probably, its most accurate definition can be considered as a "runaway" phenomenon "disappearing" in the many transformations which it undergoes at different stages of the human ontogenetic development (Mozgovaya, 2010).

One of the first researchers who turned to the use of this concept was K. Levin. In his "field theory", the concept of "psychological living space" is reflected, the content of which are objective physical and quasi-physical, objective social and quasi-social factors (Levin, 2000). K. Levin gave a description of the person as a kind of differentiated integrity, comprising its own personal space as a significant part. He considered keeping the personal space or the space of "free life movement" as one of prerequisites for establishing positive interpersonal relationships between people. K. Levin thought that the boundary of the psychological space allows saving the person integrity through regulating the process of interpenetration of "facts" in the interaction of a person and the environment (Pisachkin, 1997).

Meaningful correlates of the personal psychological space include boundaries of this space. The problem of psychological distance or compliance to boundaries is best elaborated in the works of Gestalt psychologists who have examined the subject's contacts with the environment, believing that the point of contact between the organism and the environment is the contact boundary. It is the border, according to F.S. Pearles, where psychological events are located: our thoughts, actions, our emotions, which are a form of our experience and the result of the meeting of these events on the border with the environment. Through the contact with the environment, people gain experience, form their views and outlooks, build an individual scale of values (Mozgovaya, 2002).

An interesting point of view regarding the boundaries of the personal space belongs to M.M. Bakhtin. Each inner experience on the boundary meets with others, and in this tense meeting is its essence. The threshold of the other person's consciousness, according to M.M. Bakhtin, defines the boundary of the own consciousness. I.e. the boundary of Me is determined through the boundary of the "threshold" of other person's Me (Bakhtin, 1960).

Similar ideas can be found at M. Buber, who expressed the opinion that in the plane Me-You there was a thin space of the personal "Me". It requires filling by other Me. The closer is spatial contact with of a human with other people, the more dependent is the human activity from other people and the less the freedom to choose ways of activity. Such understanding of the spatial contact indicates the connection of the external control and human activities (Suroedova, 2009).

Thus, the personal psychological space has a complex psychological structure formed by the interaction of the components reflected by the person. According to N.N. Mozgovaya, the personal space has a number of complex functions: protective (saving), representative, controlling, identifying ones (Mozgovaya, 2010). Also, the human psychological space takes place at all stages of the ontogenetic development. It has the most vivid expression at time of being a student. (Mozgovaya, 2002)

Thus, a clear sense of balance of personal psychological space boundaries is already enshrined in this age. Expansion of internal boundaries is intended to help students, including emigrants, to understand themselves, unleash their inner self and through it, to reach a new level of interaction with the world and people of other nationalities. This will require the inner freedom, self-reliance and the ability to defend the own point of view without concentrating on the complexity of life situations.

It should be noted that an important role in the process of establishing the boundaries of the personal psychological space is played by various supporting structures. Subjective factors affecting the dynamics of integration and adaptation include the personal psychological structure itself. Cognitive organization of a person, which determines the ways of perceiving, thinking, remembering and experience, has a significant influence on the formation of adaptive behavior forms, stabilization of boundaries of personal space under constant stress conditions for the emigrant, which is unfamiliar society with alien linguistic and socio-cultural standards (Khrustalyova, 1999).

Formed motivations and values are a great importance for the student-emigrant manifesting in the wish to integrate into the new environment, in the willingness to study new cultural phenomena, commitment to overcome informational isolation and establish socially acceptable relations with the environment (Khrustalyova, 1999). Important subjective factors of adaptation leading to expansion of boundaries of the personal space of a student-emigrant are such personal characteristics as high communicative potential of the subject of communication, availability of intellectual and volitional complex, ability to study, critical thinking, willingness to change the course of individual development, commitment, perseverance, responsibility, self-discipline, self-control; resistance to neural and psychic stress, self-regulation, high 
level of disability and vitality.

Provided that in the conditions of emigration, especially in the initial stages, there is predominance of highly problematic situations, uncertainty, taking non-standard solutions, the person needs such qualities as creativity, i.e. willingness to change and abandon stereotypes narrowing the personal space boundaries. Also, the speed of habituation directly depends on the migrant's age. Thus, a large effect on the rate of addiction is from the student-emigrant past, socio-economic conditions, social status, professional adaptation and requirements for a new life (Khrustalyova, 1999).

In our study we also address the problem of sense and values of the subject. In adolescence they are reassessed and undergo constant development and dynamics, not only by students-emigrants. The development of value and sense sphere is due to the influence of many factors to the emerging personality, but certainly an important role belongs to communication and interpersonal relations permeating all educational space of high school (Belousov, 2006).

In early adolescence, the person is in the stage of forming moral concepts of ideological level: the meaning of life, the happiness of man as the highest value; the person individual becomes able to do a moral choice. Assimilating values of the environment in which the student-emigrant is, and adding them to the already existing values by activating motivational forces of the own behavior, the student-emigrant becomes an active subject of social activities (Suroedova, 2009).

\section{Analysis Result}

The aim of the study was determining the relation between the values of students-emigrants and the development of their personal psychological space. In the course of empirical study of the formation and development of value and sense sphere of students of the second-fourth years of study (Rostov-on-Don), obtained results revealed not only their dynamics, but also the development of components of the personal space.

Students-emigrants of the Psychological Faculty of the second year are characterized by a high level of normative ideals, i.e. all values are estimated by the second year students high enough that characterizes a contradictory and innerconflict orientation of the person. However, the most important ones are security and kindness, social contacts expressed in good relations with the collective, pursuit to self-harmony, goodwill towards loved ones. Thus, it can be said that at this stage the young people have a diffusion of the personal space; it expands, comes into contact and mixes with spaces of other persons. The second year students have yet a personal space without clear boundaries because of the high need for communication, recognition, understanding and interpersonal contacts.

The main sphere of life for students-emigrants of the second year is the sphere of "Education and Training". This fact suggests that these respondents identify themselves with students whose task is to train and obtain professional skills and knowledge, i.e. at this stage there is the development of the following components of the personal space: high school as spatial, knowledge and skills as cognitive, student status as role and individual component.

Students-emigrants of the Psychological Faculty of the third year pay more attention to the pleasures of life, individual priorities; they have an orientation to selfishness, which is expressed in the dominance and leadership. The most important value at this stage of training is hedonism and achievement. This fact shows that at this stage the focus of the formation and development is on individual and moral component of the personal space. The main spheres of life are "Education and Training", "Professional life".

Students-emigrants of the Psychological Faculty of the fourth year are characterized by a high level of normative ideals showing a contradictory and inner conflict orientation of the person. The most significant one is the sphere of professional life. This allows saying that the fourth year respondents pass an introduction to the profession and the identification of themselves with not only the role of the student, but already a professional in their work, with a predominance of the spiritual needs over material ones. That is, there is a further development of such components of the personal space as role and moral ones.

\section{Conclusion}

So, we can say that there is a dynamic of values of students-emigrants of the Psychological Faculty of the second-fourth year; the students' values undergo some transformation in the course of training in the high school. By the end of training (the fourth year) respondents become more helpful, responsible, forgiving than they were in the second year and have an increasing need for interaction with loved ones. The great importance is of friendship and personal well-being. In the fourth year, psychology students-emigrants become more disciplined, polite, restrained, respecting parents and elders, observe the traditions and norms of behavior with a special responsibility. In the course of training in the high school respondents yearly increase values of stimulation, tradition and conformity. Students become more restrained in their 
behavior; considerable attention is paid to compliance with social norms and traditions. Human values formed in the process of professionalization become of a great value for the graduates.

There is also the dynamics of personal space of students-emigrants. At different periods there are various dominating and transforming components of the personal space. However, it should be noted that values and senses literally permeate all components, becoming a backbone both for the person and the personal space (Suroedova, 2009).

Thus, the data of the empirical study presented above showed that human values have a formative influence on all components of the personal space. Values play an important role in the development of all spheres of the person life activities influence the constituent components of the personal space.

\section{References}

Abramova G.S. (1998)/ Practical course of psychology. Moscow: Ed. center "Academia".

Bakhtin M.M. (1996). Collected edition. In 7 volumes / Institute of World Literature named after A.M. Gorky of the Russian Academy of Sciences. - Moscow: Russian dictionary.

Belousova A.K. (2002). Self-organization of joint thinking activity IA.K. Belousova, Rostov o/D: Publishing House of the Rostov State Pedagogical University.

Belousova A.K. (2006) Sense communication. Communication - 2006: on the way to the encyclopedic knowledge // Materials of the International Conference of the Psychological Institute of the Russian Academy of Education. Moscow, p. 226-228.

Levin K. (2000).Resolution of social conflicts. SPb.: "Sensor".

Mozgovaya N.N. (2002). Development of ideas about the personal space of pedagogical high school students. Candidate's dissertation by psychology. Stavropol.

Mozgovaya N.N. (2010). Personal space as an object of study // News of the Southern Federal University. Pedagogical sciences. No. 12. 2010

Parygin B.D. (1999). Anatomy of communication. SPb.: Publishing House of V.A. Mikhailov.

Pisachkin V.A. (1997) Sociology of the living space. Saransk: MU.

Suroedova E.A. (2009). Meanings and sense communication in the educational space // News of the Don State Technical University. V.9. Rostov o/D. 2009, p. 113-122.

Hrustaleva N. (1999) Adaptation of immigrants from the former Soviet Union. Psychologist's View // Expat communities. No. 2-3, p.142 